\title{
Advanced age and apnea-hypopnea index predict subclinical atherosclerosis in patients with obstructive sleep apnea syndrome
}

\author{
Bilal Arik', Mehmet Fatih Inci ${ }^{2}$, Cesur Gumus ${ }^{1}$, Kenan Varol ${ }^{1}$, Meltem Refiker Ege ${ }^{3}$, Omer Tamer Dogan ${ }^{4}$ \\ and Ali Zorlu ${ }^{5}$
}

\begin{abstract}
Background: Both obstructive sleep apnea syndrome (OSAS) and coronary artery calcification (CAC) are considered to be related with the presence of coronary artery disease (CAD). In this study we evaluate the association between OSAS and presence of subclinical atherosclerosis assessed by tomographic coronary calcium score in patients who had OSAS but no history of known CAD.

Methods: Seventy-three patients who were asymptomatic for CAD and had suspected OSAS were referred to overnight attended polysomnography. Patients were classified into 4 groups according to the Apnea-Hypopnea Index (AHI). All patients underwent computed tomographic examination for tomographic coronary calcification scoring. Physical examination, sleep study recordings, complete blood count and serum biochemistry were obtained from all patients.

Results: In the whole group, AHI levels were weakly correlated with coronary calcium score $(r=0.342, p=0.003)$ and body mass index $(r=0.337, p=0.004)$, moderately correlated with basal oxygen saturation $(r=-0.734$, $p<0.001)$, and strongly correlated with oxygen desaturation index $(r=0.844, p<0.001)$. In an univariate analysis, age, AHI, basal oxygen saturation, and oxygen desaturation index were associated with CAC in patients with OSAS. In a multiple logistic regression model, age (OR 1.108,\%95 Cl 1.031-1.191, $\mathrm{p}=0.005)$ and $\mathrm{AHI}(\mathrm{OR} 1.036, \% 95 \mathrm{Cl}$ 1.003-1.070, $p=0.033$ ) were only independent predictors of CAC in patients with OSAS with a sensitivity of $88.9 \%$ and $77.8 \%$ and a specificity of $54.3 \%$ and $56.5 \%$ respectively.
\end{abstract}

Conclusions: Our findings suggest that in patients with moderate or severe OSAS and advanced age, physicians should be alert for the presence of subclinical atherosclerosis.

Keywords: Age, Apnea hypopnea index, Coronary calcium score, Obstructive sleep apnea syndrome, Subclinical atherosclerosis

\section{Background}

Obstructive sleep apnea syndrome (OSAS) is a respiratory disorder of sleep characterized by recurrent episodes of complete or partial airway obstruction, associated with intermittent arterial oxygen desaturation. The repetitive nocturnal hypoxemia experienced by patients with OSAS is associated with activation of a number of neural, humoral, thrombotic, metabolic, and inflammatory disease

\footnotetext{
* Correspondence: drfatihinci@gmail.com

${ }^{2}$ Department of Radiology, Sütçü Imam University Medical School, Kahramanmaras, Turkey

Full list of author information is available at the end of the article
}

mechanisms, all of which play a role in the pathophysiology of cardiac and vascular diseases [1-3]. Moreover, several etiological factors in OSAS overlap with those of cardiovascular diseases making it difficult to distinguish the direct cardiovascular consequences of OSAS from its role in exacerbating concomitant cardiovascular disease $[4,5]$. OSAS is also associated with obesity, hypertension and metabolic dysregulation which themselves contribute to endothelial dysfunction [6,7]. In recent studies $[8,9]$ the association of OSAS and coronary artery disease (CAD) has been documented.

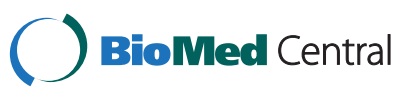


Coronary artery calcification (CAC) has been shown to be highly specific for atherosclerosis and coronary artery calcium measurements have been revealed as a tool for risk stratification [10]. In a study utilizing tomographic coronary calcium score conducted by Detrano et al., it was suggested that the presence and extent of CAC is strongly correlated with the overall atherosclerotic plaque burden and with the development of coronary events [11].

In the present study we evaluate the association between OSAS and presence of subclinical atherosclerosis assessed by tomographic coronary calcium scoring in patients who had been referred to polysomnographic examination for clinically suspected OSAS and had no history of known CAD.

\section{Methods}

\section{Study population}

The study included 85 consecutive patients who were referred to polysomnography for clinically suspected OSAS. Patients with previous history of CAD diagnosed by coronary angiography, with the diagnosis of recent acute coronary syndrome (within the last 2 months), those with unstable angina or suspected cardiac ischemia on noninvasive tests, those with acute pulmonary infection, congenital heart disease, cardiac rhythm other than sinus, chronic renal failure, and insufficient clinical data were excluded. Finally, 73 patients (43 males, 30 females, mean age $50 \pm 10$ years), who were asymptomatic for CAD, had suspected OSAS, and had undergone computed tomographic examination for tomographic coronary calcification scoring, were prospectively enrolled.

The following data also were recorded at hospitalization: age, gender, body mass index, atherosclerotic risk factors such as hypertension, diabetes mellitus, hyperlipidemia, and smoking habit, alcohol consumption and current medications. Smoking was defined as current cigarette smoking, and abstinence $\leq 2$ years. Hypertension was defined as

Table 1 Baseline characteristics of the patients

\begin{tabular}{ll}
\hline & All patients $(\mathbf{n}=\mathbf{7 3})$ \\
\hline Age, years & $50 \pm 10$ \\
Male/Female & $43 / 30$ \\
Diabetes mellitus, $\mathrm{n}(\%)$ & $21(29 \%)$ \\
Hypertension, $\mathrm{n}(\%)$ & $27(37 \%)$ \\
Smoking, $\mathrm{n}(\%)$ & $38(52 \%)$ \\
Body mass index, kg/m² & $30.1 \pm 5.2$ \\
Hyperlipidemia, $\mathrm{n}(\%)$ & $21(29 \%)$ \\
Apnea-hypopnea index (min-max) & $22.8 \pm 19.8(1-95)$ \\
Basal oxygen saturation,\% & $81 \pm 14$ \\
Oxygen desaturation index (min-max) & $6.8 \pm 8.3(0-47)$ \\
Coronary calcium score (min-max) & $28.6 \pm 87.8(0-480)$ \\
Presence of coronary artery calcification, $\mathrm{n}(\%)$ & $27(37 \%)$ \\
\hline
\end{tabular}

blood pressure $\geq 140 / 90 \mathrm{mmHg}$ on two or more measurements or being on antihypertensive medication. Diabetes mellitus was defined as fasting glucose $\geq 126 \mathrm{mg} / \mathrm{dl}$ and/ or using an antidiabetic medication. Hyperlipidemia was defined as fasting total serum cholesterol more than 200 $\mathrm{mg} / \mathrm{dl}$ and/or being on oral lipid-lowering agent. Physical examination, sleep study recordings, complete blood count and serum biochemistry were obtained from all patients.

Written informed consent was obtained from all patients and the study was approved by the Ethics Committee.

\section{Polysomnography}

Patients with suspected OSAS were referred to overnight attended polysomnography(Somnostar 4100; SensorMedics Co., Yorba Linda, CA) with continuous recordings including electroencephalography, electrooculography, submental and leg electromyography, electrocardiography, tracheal sounds, noninvasive sensors for nasal or oral airflow, thoracic and abdominal respiratory movement and oxyhemoglobin level (Sat-Trak finger-pulse oximeter; SensorMedics Co). Sleep stages were manually scored using the methods of Rechtschaffen et al. [12]. Apneas were defined as a complete cessation of airflow lasting $\geq 10$ seconds, and hypopnea was defined as reduction of $\geq 50 \%$ in airflow from the baseline value lasting $\geq 10$ seconds and associated with 3\% desaturation or an arousal. The Apnea-Hypopnea Index (AHI) was established as the ratio of the number of episodes of apnea and hypopnea per hour of sleep. Patients with $\mathrm{AHI}<5$ were included in the simple snoring group (Group 1). OSAS was defined if AHI was $\geq 5$ events/ hour. Mild OSAS was defined as AHI 5 to 15/h (Group 2), moderate OSAS was defined as AHI 16 to 29/h (Group 3) and severe OSAS was defined as AHI $\geq 30 / h$ (Group 4). The oxygen desaturation index was defined as the number of events in which oxygen saturation falls below $90 \%$ per hour of sleep [13-15]. The oxygen desaturation index, basal oxygen saturation and average oxygen saturation values were also recorded.

\section{Cardiac multislice computed tomography (MSCT) analysis} Computed tomography examinations were performed with an unenhanced, electrocardiogram gated, MSCT scanner (Philips Brilliance 16 Slice CT Scanner, Holland) set at a $0.75 \mathrm{~mm}$ section thickness with a gantry rotation time of $330 \mathrm{msec}$ and a kernel value of B25f. Total coronary artery calcium score was calculated by the Agatston method as the sum of lesion scores from the four major coronary arteries (left main, left anterior descending, left circumflex, and right coronary arteries) [16].

\section{Statistical analysis}

Parametric data were expressed as mean \pm standard deviation or range (min-max), and categorical data as percentages. SPSS 17.0 (SPSS, Inc., Chicago, Illinois) was used to 
Table 2 Comparison of cardiovascular risk factors and obstructive sleep apnea related hypoxia parameters of patients according to the apnea-hypopnea index

\begin{tabular}{|c|c|c|c|c|c|}
\hline & $\begin{array}{l}\text { Group } 1 \\
(\mathrm{AHI}<5) \\
(\mathrm{n}=16)\end{array}$ & $\begin{array}{l}\text { Group } 2 \\
\text { (AHI 5-15) } \\
(\mathrm{n}=14)\end{array}$ & $\begin{array}{l}\text { Group } 3 \\
\text { (AHI 16-29) } \\
(n=19)\end{array}$ & $\begin{array}{l}\text { Group } 4 \\
(\mathrm{AHI} \geq 30) \\
(\mathrm{n}=24)\end{array}$ & $\mathbf{P}$ \\
\hline Age, years & $50 \pm 10$ & $48 \pm 9$ & $47 \pm 9$ & $52 \pm 10$ & 0.282 \\
\hline Male/Female & $9 / 7$ & $6 / 8$ & $13 / 6$ & $15 / 9$ & 0.498 \\
\hline Diabetes mellitus & $4(25 \%)$ & $2(14 \%)$ & $6(32 \%)$ & $9(38 \%)$ & 0.473 \\
\hline Hypertension & $6(38 \%)$ & $5(36 \%)$ & $4(21 \%)$ & $12(50 \%)$ & 0.281 \\
\hline Smoking & $6(38 \%)$ & $7(50 \%)$ & $11(58 \%)$ & $14(58 \%)$ & 0.568 \\
\hline Body mass index, kg/m2 & $28.2 \pm 4.8$ & $30.9 \pm 6.4$ & $28.4 \pm 4.8$ & $32.2 \pm 4.1$ & 0.035 \\
\hline Hyperlipidemia & $6(38 \%)$ & $3(21 \%)$ & $3(16 \%)$ & $9(38 \%)$ & 0.332 \\
\hline \multirow[t]{2}{*}{ Apnea-hypopnea index (min-max) } & $2.4 \pm 1.1$ & $8.0 \pm 2.0$ & $22.5 \pm 4.3$ & $45.3 \pm 16.3$ & $<0.001$ \\
\hline & $(1-4)$ & $(6-12)$ & $(16-28)$ & $(30-95)$ & \\
\hline Basal oxygen saturation, $\%$ & $94 \pm 6$ & $87 \pm 10$ & $77 \pm 12$ & $71 \pm 12$ & $<0.001$ \\
\hline \multirow[t]{2}{*}{ Oxygen desaturation index (min-max) } & $0.7 \pm 2.7$ & $2.7 \pm 3.2$ & $5.1 \pm 3.3$ & $14.6 \pm 19.7$ & $<0.001$ \\
\hline & $(0-11)$ & $(0-10)$ & $(0-12)$ & $(2-47)$ & \\
\hline \multirow[t]{2}{*}{ Coronary calcium score (min-max) } & $1.4 \pm 3.0$ & $1.9 \pm 4.9$ & $32.2 \pm 97.5$ & $59.5 \pm 121.2$ & 0.015 \\
\hline & $(0-11)$ & $(0-15)$ & $(0-420)$ & $(0-480)$ & \\
\hline Presence of coronary artery calcification & $4(25 \%)$ & $2(14 \%)$ & 7 (37\%) & $14(58 \%)$ & 0.032 \\
\hline
\end{tabular}

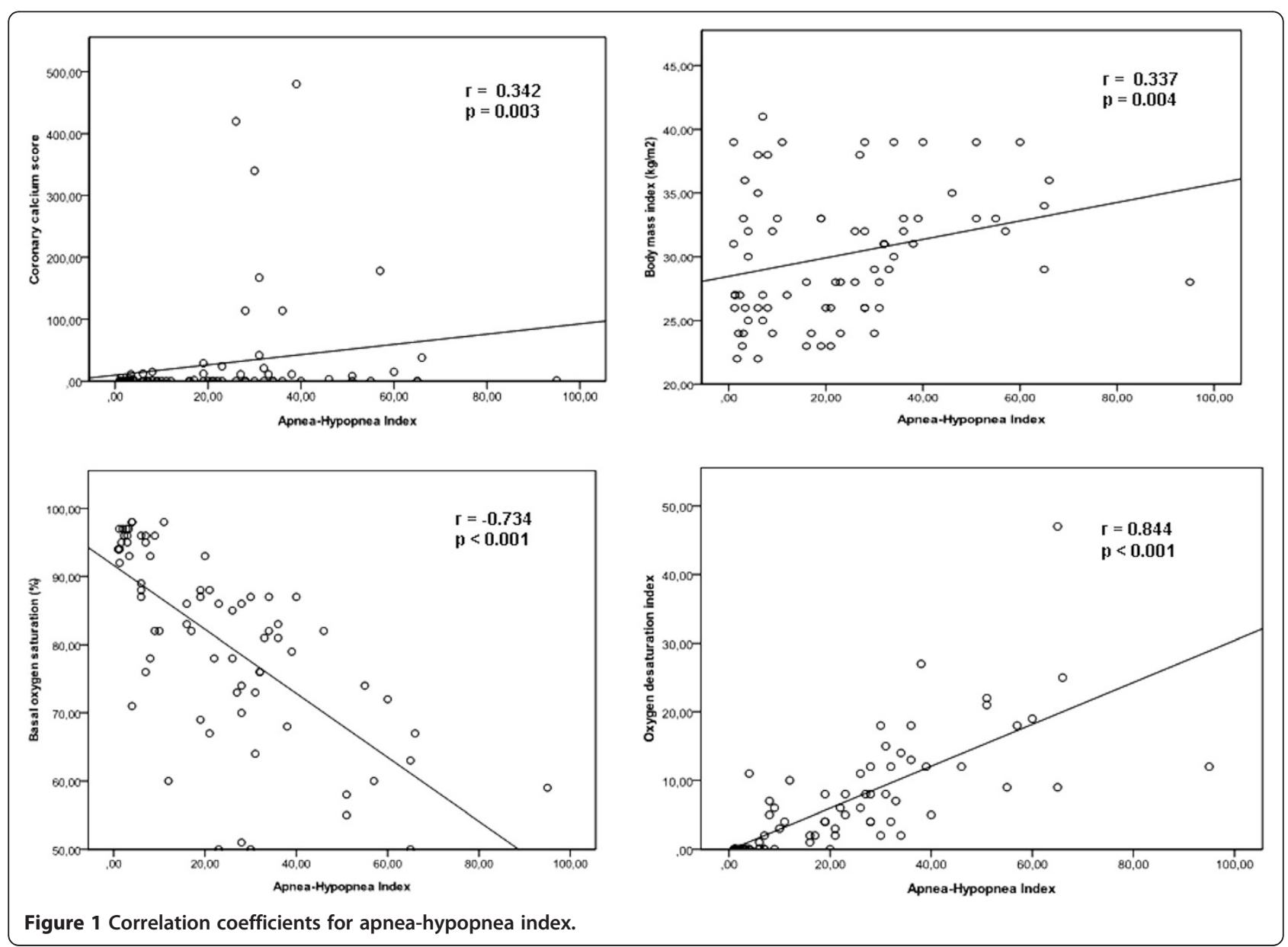


Table 3 Comparison of cardiovascular risk factors and obstructive sleep apnea related hypoxia parameters of patients with obstructive sleep apnea $(\mathrm{AHI} \geq 5, \mathrm{n}=57$ ) according to the presence of coronary calcium

\begin{tabular}{llll}
\hline & $\begin{array}{l}\text { Coronary artery calcification }(-) \\
(\mathbf{n}=\mathbf{3 4})\end{array}$ & $\begin{array}{l}\text { Coronary artery calcification }(+) \\
(\mathbf{n}=\mathbf{2 3})\end{array}$ \\
\hline Age, years & $46 \pm 10$ & $54 \pm 7$ & $\mathbf{p}$ \\
Male/Female & $18 / 16$ & $16 / 7$ & 0.002 \\
Diabetes mellitus & $7(21 \%)$ & $10(44 \%)$ & 0.327 \\
Hypertension & $12(35 \%)$ & $9(39 \%)$ & 0.064 \\
Smoking & $19(56 \%)$ & $13(57 \%)$ & 0.988 \\
Body mass index, $\mathrm{kg} / \mathrm{m} 2$ & $30.3 \pm 5.7$ & $31.1 \pm 4.3$ & 0.962 \\
Hyperlipidemia & $9(27 \%)$ & $6(26 \%)$ & 0.590 \\
Apnea-hypopnea index & $23.7 \pm 16.5(1-65)$ & $35.5 \pm 20.1(1-95)$ & 0.974 \\
Basal oxygen saturation, $\%$ & $79.5 \pm 13.7$ & $73.9 \pm 11.1$ & 0.019 \\
Oxygen desaturation index & $7.0 \pm 8.9(0-47)$ & $10.8 \pm 7.5(0-27)$ & 0.108 \\
\hline
\end{tabular}

perform statistical procedures. Independent parameters were compared by Independent sample's $t$ test, and if there was no normal distribution, by Mann Whitney $U$ test. Categorical data were evaluated by chi square test as appropriate. Correlations were evaluated by Spearman correlation test. Receiver operator characteristic (ROC) curve analysis was performed to identify the optimal cut-off point of AHI and age (at which sensitivity and specificity would be maximal) for the prediction of identify CAC. Areas under the curve (AUC) were calculated as measures of the accuracy of the tests. We compared the AUC with use of the Z test. Univariate analysis was used to quantify the association of variables with coronary artery calcification. Variables found to be statistically significant with univariate analysis were used in a multiple logistic regression model with forward stepwise method in order to determine the independent predictors of CAC in patients with OSAS. A p value $<0.05$ was accepted as statistically significant.

\section{Results}

A total of 73 patients who were referred to polysomnography for clinically suspected OSAS were evaluated. Out of these patients, $43(58.9 \%)$ were male and $30(41.1 \%)$ were

Table 4 Univariate predictors of coronary artery calcification in patients with OSAS

\begin{tabular}{llll}
\hline & $\mathbf{p}$ & OR & $\mathbf{( 9 5 \% ~ C l )}$ \\
\hline Age, years & 0.007 & 1.080 & $1.022-1.142$ \\
Apnea-hypopnea index & 0.014 & 1.034 & $1.007-1.063$ \\
Basal oxygen saturation,\% & 0.026 & 0.959 & $0.924-0.995$ \\
Oxygen desaturation index & 0.038 & 1.073 & $1.004-1.147$ \\
Presence of Diabetes mellitus & 0.087 & 2.475 & $0.875-6.997$ \\
Presence of Hypertension & 0.768 & 0.848 & $0.284-2.533$ \\
Body mass index, kg/m2 & 0.582 & 1.029 & $0.928-1.141$ \\
\hline
\end{tabular}

$\mathrm{Cl}$, Confidence interval; OR, Odds ratio. female. The mean age was $50 \pm 10$ years. The mean AHI, basal oxygen saturation, oxygen desaturation index and coronary calcium score were found as $22.8 \pm 19.8$ (1-95), $81 \pm 14 \%, 6.8 \pm 8.3(0-47)$ and $28.6 \pm 87.8$ (0-480), respectively (Table 1 ).

The demographic characteristics and risk factors of patients classified according to the severity of OSAS are represented in Table 2. There were no significant differences between groups regarding age, gender, prevalence of diabetes mellitus, hypertension, hyperlipidemia and smoking. There were significant differences between the groups regarding body mass index, basal oxygen saturation, oxygen desaturation index, $\mathrm{AHI}$, presence of coronary artery calcification and coronary calcium score. AHI levels were weakly correlated with coronary calcium score $(r=0.342$, $\mathrm{p}=0.003)$ and body mass index $(\mathrm{r}=0.337, \mathrm{p}=0.004)$, moderately correlated with basal oxygen saturation $(r=-0.734$, $\mathrm{p}<0.001$ ), and strongly correlated with oxygen desaturation index $(\mathrm{r}=0.844, \mathrm{p}<0.001)$ (Figure 1).

Table 3 demonstrates the polysomnograpic findings and risk factors of patients according to the presence of coronary calcification. The patients in the group who had coronary artery calcification were older with marginally significant higher prevalence of diabetes mellitus. AHI and oxygen desaturation index were significantly higher, and the basal oxygen saturation values were significantly lower, in the group who had coronary artery calcification.

In the univariate regression analysis, age, AHI, basal oxygen saturation, and oxygen desaturation index were

Table 5 Multivariate predictors of coronary artery calcification in patients with OSAS

\begin{tabular}{llll}
\hline & $\mathbf{p}$ & $\mathbf{O R}$ & $\mathbf{( 9 5 \% ~ C l )}$ \\
\hline Age, years & 0.005 & 1.108 & $1.031-1.191$ \\
Apnea hypopnea index & 0.033 & 1.036 & $1.003-1.070$ \\
\hline
\end{tabular}

$\mathrm{Cl}$, Confidence interval; OR, Odds ratio. 


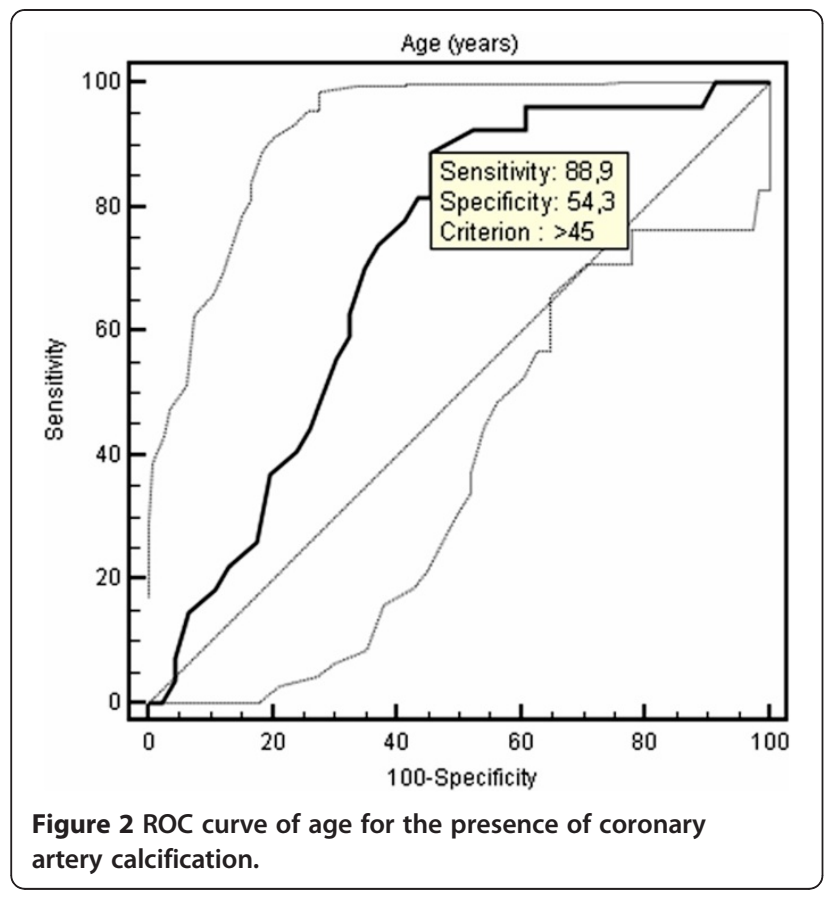

associated with CAC in patients with OSAS (Table 4). In the multiple logistic regression analysis, age (OR 1.108,\% 95 CI 1.031-1.191, $\mathrm{p}=0.005)$ and AHI (OR 1.036,\% 95 CI $1.003-1.070, \mathrm{p}=0.033$ ) were only independent predictors of CAC in patients with OSAS after adjustment of potential confounders (Body mass index, presence of hypertension and diabetes mellitus) and variables found to be statistically significant in univariate analysis (Table 5).

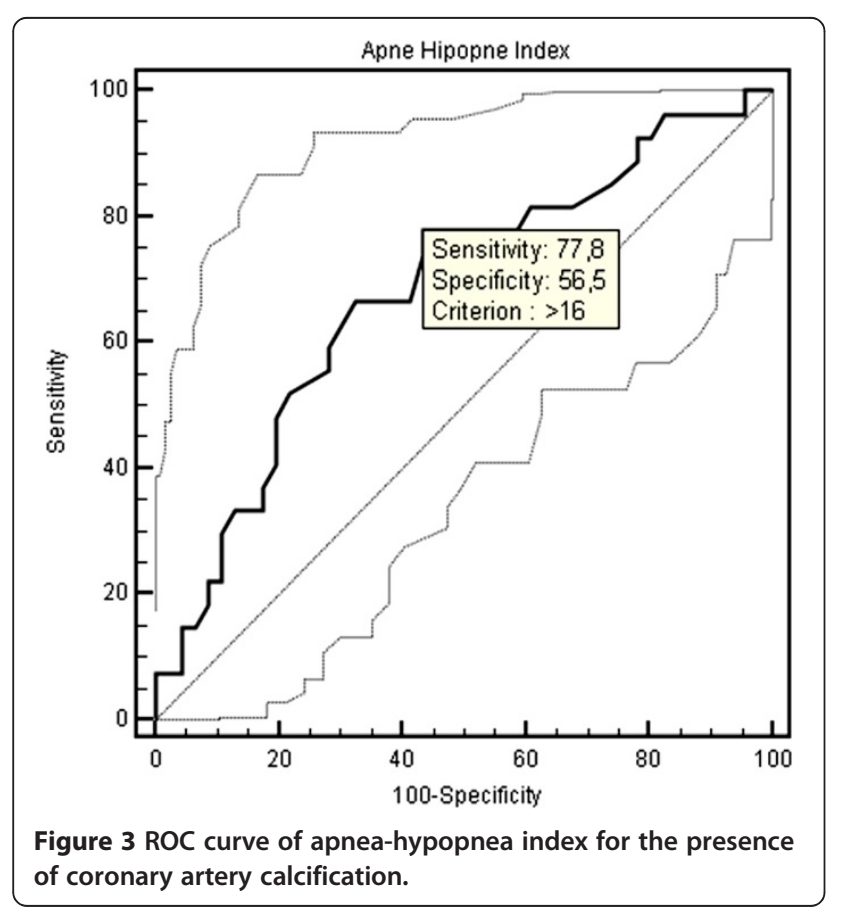

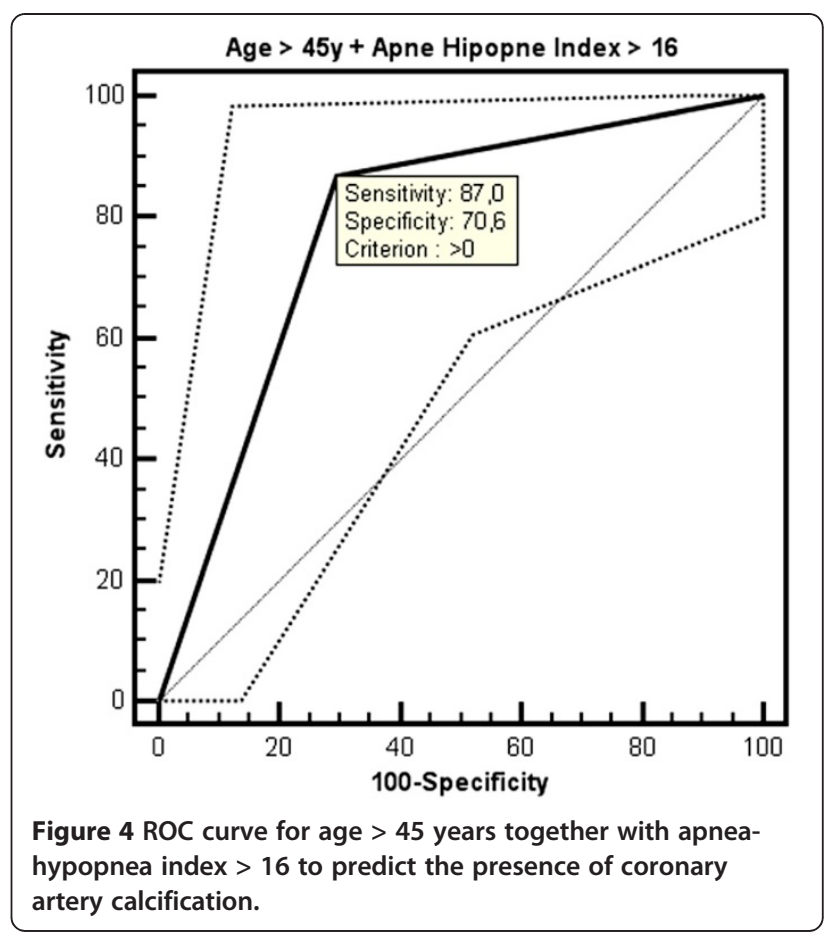

All the variables from Table 1 were examined and only those significant at a $\mathrm{p}<0.05$ level and those with a correlated age and apnea-hypopnea index levels (Body mass index, presence of hypertension and diabetes mellitus) are shown in univariate analysis.

The multiple logistic regression model included all univariate predictors and those with correlated age and apnea hypopnea index levels (Body mass index, presence of hypertension and diabetes mellitus).

The optimal cut-off point of age for the prediction of CAC was $>45$ years with a sensitivity of $88.9 \%$ and a specificity of $54.3 \%$ (AUC: $0.711,95 \%$ CI: 0,593 to 0,811 , Figure 2). The optimal cut-off point of AHI for the prediction of CAC was > 16 with a sensitivity of $77.8 \%$ and a specificity of $56.5 \%$ (AUC: 0.682 , 95\% CI: 0,563 to 0,786, Figure 3). An additional ROC analysis also showed that considering the age $>45$ and $\mathrm{AHI}>16$ together in patients with OSAS, specificity increased with unchanged sensitivity for predicting subclinical atherosclerosis $(87 \%$ sensitivity, $70.6 \%$ specificity, AUC: 0.788 , 95\% CI: 0.665-0.910, Figure 4).

\section{Discussion}

Our study demonstrated that age, AHI, basal oxygen saturation, oxygen desaturation index and presence of diabetes mellitus were associated with CAC in patients with OSAS. However, even after controlling these parameters, age and AHI were the only independent predictors of subclinical atherosclerosis in patients with OSAS. 
Obstructive sleep apnea which occurs in approximately $9-24 \%$ of the general population [17] is an emerging cardiovascular risk factor $[4,5]$. The Sleep Heart Health Study showed a modest increase in the odds ratio of CAD in patients with severe OSAS compared to controls [2]. Hung et al. [18] also reported that in patients with myocardial infarction, OSAS was a strong risk factor as obesity, smoking and hypertension. In a group of 23 OSAS patients without symptoms or history of CAD, about onethird showed asymptomatic ST-segment depression during sleep, but only one patient was found to have positive exercise stress test result, suggesting a low prevalence of symptomatic CAD in OSAS [19]. Therefore determination of subclinical atherosclerosis in patients with OSAS can be important in order to prevent the adverse cardiovascular events.

Although in recent studies $[20,21]$ increased cardiovascular morbidity have been confirmed in patients with OSAS, the occurrence of other cardiovascular risk factors often limited the assessment of an independent pathogenetic role for OSAS. Whereas in our study, although there was no difference in regard to the presence of cardiovascular risk factors, when patients were evaluated according to the severity of OSAS we found that the number of patients who had coronary calcification were higher in the group with higher $\mathrm{AHI}$ and the patients with higher AHI had significantly higher coronary calcium score compared to patients with lower AHI. On the other hand, when OSAS patients were evaluated according to the presence of coronary calcium, it was found that patients with coronary calcium were significantly older and had marginally significant higher prevalence of diabetes mellitus with higher AHI. Our study showed that the severity of OSAS was related to subclinical atherosclerosis irrespective of the presence of other cardiovascular risk factors except for age. Thus, it may be suggested that the presence of OSAS is a marker of subclinical atherosclerosis dependent on increasing age and the severity of subclinical atherosclerosis correlates with the severity of OSAS.

A recent study conducted by Sorajja et al. revealed that increasing severity of OSAS was related to an increase in the severity of CAC independent from other risk factors [22]. To confirm this study, our results showed that the risk of subclinical atherosclerosis was increasing with a sensitivity of $77.8 \%$ when $\mathrm{AHI}>16$ which is an indicator of moderate-to-severe OSAS. Besides, Kepez et al. observed that the relationship between the severity of OSAS and the increase in cardiovascular risk was dependent only on the age of patients [23]. On the contrary, our results demonstrate that the level of AHI and advanced age are independently associated with the development of CAC. Regardless of the severity of OSAS, patient's age $>45$ becomes an indicator of cardiovascular risk with the sensitivity of $88.9 \%$. An additional ROC analysis also showed that considering the age $>45$ and AHI > 16 together in patients with OSAS, specificity increased with unchanged sensitivity for predicting subclinical atherosclerosis $(87 \%$ sensitivity, $70.6 \%$ specificity).

Although the mechanisms underlying cardiovascular disease in patients with OSAS are still poorly understood, endothelial dysfunction, oxidative stress, and inflammation are long-term consequences that mediate cardiovascular disease in patients with OSAS [24-27]. An important mechanism of atherosclerosis in OSAS is inflammation resulting in endothelial dysfunction [24]. Several mediators that have been implicated in the pathogenesis of atherosclerosis are abnormal in patients with OSAS. C-reactive protein, a marker of systemic inflammation, and endothelin-1, a potent long-acting vasoconstricting substance are shown to be elevated in OSAS [25]. Moreover, intermittent hypoxia and reperfusion during repetitive episodes of nocturnal apnea may be involved in the generation of highly reactive oxygen radicals, as well as in ischemia-reperfusion injury to the vascular wall, resulting in increased risk for atherosclerosis [26,27].

\section{Conclusions}

In conclusion, in patients with moderate or severe OSAS and age greater than 45 , physicians should be alert for the presence of subclinical atherosclerosis in order to prevent adverse cardiovascular outcomes.

\section{Competing interest}

The authors declare that they have no conflict of interest.

\section{Author details}

'Department of Radiology, Cumhuriyet University Medical School, Sivas, Turkey. ${ }^{2}$ Department of Radiology, Sütçü Imam University Medical School, Kahramanmaras, Turkey. ${ }^{3}$ Department of Cardiology, Kavaklidere Umut Hospital, Ankara, Turkey. ${ }^{4}$ Department of Chest Diseases, Cumhuriyet University Medical School, Sivas, Turkey. ${ }^{5}$ Depatment of Cardiology, Private Malatya Hospital, Malatya, Turkey.

Received: 15 November 2012 Accepted: 4 January 2013 Published: 6 February 2013

\section{References}

1. Phillipson EA: Sleep apnea-a major public health problem. N Engl J Med 1993, 328:1271-1273.

2. Shahar E, Whitney CW, Redline S, Lee ET, Newman AB, Javier Nieto F, O'Connor GT, Boland LL, Schwartz JE, Samet JM: Sleep-disordered breathing and cardiovascular disease: cross-sectional results of the sleep heart health study. Am J Respir Crit Care Med 2001, 163:19-25.

3. Peppard PE, Young T, Palta M, Skatrud J: Prospective study of the association between sleep disordered breathing and hypertension. N Engl J Med 2000, 342:1378-1384.

4. Campos-Rodriguez F, Peña-Griñan N, Reyes-Nuñez N, De la Cruz-Moron I, Perez-Ronchel J, De la Vega-Gallardo F, Fernandez-Palacin A: Mortality in obstructive sleep apnea-hypopnea patients treated with positive airway pressure. Chest 2005, 128:624-633.

5. Doherty LS, Kiely JL, Swan V, McNicholas WT: Long-term effects of nasal continuous positive airway pressure therapy on cardiovascular outcomes in sleep apnea syndrome. Chest 2005, 127:2076-2084.

6. Budhiraja R, Tuder RM, Hassoun PM: Endothelial dysfunction in pulmonary hypertension. Circulation 2004, 109:159-165. 
7. Davignon J, Ganz P: Role of endothelial dysfunction in atherosclerosis. Circulation 2004, 109:27-32.

8. Gordon P, Sanders MH: Sleep. 7: positive airway pressure therapy for obstructive sleep apnoea/hypopnoea syndrome. Thorax 2005, 60:68-75.

9. Giles TL, Lasserson TJ, Smith BH, White J, Wright J, Cates CJ: Continuous positive airways pressure for obstructive sleep apnoea in adults. Cochrane Database Syst Rev 2006, 3:CD001106.

10. Sangiorgi G, Rumberger JA, Severson A, Edwards WD, Gregoire J, Fitzpatrick $L A$, Schwartz RS: Arterial calcification and not lumen stenosis is highly correlated with atherosclerotic plaque burden in humans: a histologic study of 723 coronary artery segments using nondecalcifying methodology. J Am Coll Cardiol 1998, 31:126-133.

11. Detrano R, Guerci AD, Carr JJ, Bild DE, Burke G, Folsom AR, Liu K, Shea S, Szklo M, Bluemke DA, O'Leary DH, Tracy R, Watson K, Wong ND, Kronmal RA: Coronary calcium as a predictor of coronary events in four racial or ethnic groups. N Engl J Med 2008, 358:1336-1345.

12. Rechtshaffen A, Kales A: A manual of standardized terminology, techniques and scoring system for sleep stages of human subjects. Bethesda: National Institutes of health; 1968. NIH Publication No.2941.

13. Sleep-related breathing disorders in adults: recommendations for syndrome definition and measurement techniques in clinical research. The Report of an American Academy of Sleep Medicine Task Force. Sleep 1999, 22:667-689.

14. EEG arousals: scoring rules and examples: a preliminary report from the Sleep Disorders Atlas Task Force of the American Sleep Disorders Association. Sleep 1992, 15:173-184.

15. Meoli AL, Casey KR, Clark RW, Jr Coleman JA, Fayle RW, Troell RJ, Iber C: Clinical practice review committee. Hypopnea in sleep-disordered breathing in adults. Sleep 2001, 24:469-470.

16. Agatston AS, Janowitz WR, Hildner FJ, Zusmer NR, Jr Viamonte M, Detrano $R$ : Quantification of coronary artery calcium using ultrafast computed tomography. J Am Coll Cardiol 1990, 15:827-832.

17. Young T, Palta M, Dempsey J, Skatrud J, Weber S, Badr S: The occurrence of sleep-disordered breathing among middle-aged adults. N Engl J Med 1993, 328:1230-1235.

18. Hung J, Whitford EG, Parsons RW, Hillman DR: Association of sleep apnea with myocardial infarction in men. Lancet 1990, 336:261-264.

19. Hanly P, Sasson Z, Zuberi N, Lunn K: ST-segment depression during sleep in obstructive sleep apnea. Am J Cardiol 1993, 71:1341-1345.

20. Zaninelli A, Fariello R, Boni E, Corda L, Alicandri C, Grassi V: Snoring and risk of cardiovascular disease. Int J Cardiol 1991, 32:347-351.

21. Peker Y, Hedner J, Norum J, Kraiczi H, Carlson J: Increased incidence of cardiovascular disease in middle-aged men with obstructive sleep apnea: a 7-year follow-up. Am J Respir Crit Care Med 2002, 166:159-165.

22. Sorajja D, Gami AS, Somers VK, Behrenbeck TR, Garcia-Touchard A, LopezJimenez F: Independent association between obstructive sleep apnea and subclinical coronary artery disease. Chest 2008, 133:927-933.

23. Kepez A, Niksarlıoğlu EY, Hazııolan T, Hayran M, Kocabaș U, Demir AU, Aytemir K, Tokgözoğlu L, Nazlı N: Evaluation of association between obstructive sleep apnea and coronary risk scores predicted by tomographic coronary calcium scoring in asymptomatic patients. Anadolu Kardiyol Derg 2011, 11:428-435.

24. Phillips BG, Narkiewicz K, Pesek CA, Haynes WG, Dyken ME, Somers VK: Effects of obstructive sleep apnea on endothelin-1 and blood pressure. J Hypertens 1999, 17:61-66.

25. Shamsuzzaman AS, Winnicki M, Lanfranchi P, Wolk R, Kara T, Accurso V Somers VK: Elevated C-reactive protein in patients with obstructive sleep apnea. Circulation 2002, 105:2462-2464.

26. Dean RT, Wilcox I: Possible atherogenic effects of hypoxia during obstructive sleep apnea. Sleep 1993, 16:15-21.

27. Halliwell B: The role of oxygen radicals in human disease, with particular reference to the vascular system. Haemostasis 1993, 23:118-126.

doi:10.1186/2049-6958-8-9

Cite this article as: Arik et al: Advanced age and apnea-hypopnea index predict subclinical atherosclerosis in patients with obstructive sleep apnea syndrome. Multidisciplinary Respiratory Medicine 2013 8:9.

\section{Submit your next manuscript to BioMed Central and take full advantage of:}

- Convenient online submission

- Thorough peer review

- No space constraints or color figure charges

- Immediate publication on acceptance

- Inclusion in PubMed, CAS, Scopus and Google Scholar

- Research which is freely available for redistribution

Submit your manuscript at www.biomedcentral.com/submit
() Biomed Central 